\title{
The role of resilience in the relationship between stressful life events and health in a Romanian sample
}

\author{
Alina Chiracu ${ }^{l *}$ \\ ${ }^{1}$ Departament of Psychology, University of Bucharest, Romania.
}

Received 5.08.2019; Received revised 21.12.2019; Accepted 28.12.2019

Available online 31.12.2019

\begin{abstract}
This study aims to identify the moderator role of resilience in the relationship between exposure to stressful life events and health state. The study included 238 participants from the general Romanian population, aged between 23 and 68 years, $\mathrm{M}=44.16, \mathrm{SD}=11.03,188$ women and 50 men. The instruments used were Stressful Life Event Questionnaire, Resilience Scale, RS-14, and General Health Questionnaire, GHQ-12. The results revealed that resilience moderates the relationship between stressful life events and health state, but contrary to our expectations, in a negative direction. The negative relationship between exposure to stressful life events and mental health became non-significant at lower levels of resilience and higher levels of resilience failed to buffer the effects of stressful life events on mental health of the individual. These results extend the current knowledge about resilience's role in individual's health state after confronting with stressful life events. The implications of the findings, the limitations, and future research directions were discussed.
\end{abstract}

Keywords: stressful life events, resilience, health state.

Address of correspondence: Alina Chiracu, Departament of Psychology, University of Bucharest, Panduri Street, No. 90, Sector 5, Bucharest, Romania.

E-mail: alina.chiracu@drd.unibuc.ro

\section{Introduction}

Stressful life events can have a major impact on individuals who experience them. Coping with stressful events is a risk factor for the person's health and for his overall well being. Resilience is an important factor that can intervene in the relationship between exposure to stressful life events and individual general health state. In turn, resilience can be shaped by the life experience of the person and by environmental factors, thus constituting a constantly growing construct.

\section{Stressful life events and their negative effects}

Most studies have pointed out that stressful life experiences have negative effects, and the main negative outcomes are depression and anxiety (Nolen-Hoeksema \& Morrow, 1991) or cognitive disruptions such as ruminations or intrusive thoughts which profoundly affect the normal functioning of the person and his or her adaptation to daily life (Shaham, Singer, \& Schaeffer, 1992).

There are numerous theories that support the presence of negative consequences of exposure to stressful life events. Horowitz (1976) and, later, Silver, Boon, and
Stones (1983) argue that most of the negative effects of stressful life events result from the person's difficulties in reconstructing a viable cognitive schema. This reconstruction is closely linked to the individual's need to find a meaning in the event and to the efforts to manage the implications of the event. In this view, adverse events can have a long-term impact, during which time the individual will face a diminished ability to successfully cope with other possible stressful events, thus leading to a marked vulnerability to possible aversive situations.

The assumptive world theory (Janoff-Bulman, 1992) proposes that traumatized individuals cannot maintain positive perceptions of themselves and others and cannot hold a belief in a just and meaningful world. Stressful life events thus lead to diminished self-concept and loss of confidence in others and in the world, thus shaking the fundamental assumptions of the individual. From this perspective, these shattered assumptions can lead to distress and the risk of developing depression or anxiety.

The mechanisms by which stressful life events impact health status have been extensively documented over time. According to Selye (1956), stress operates in three phases: alarm, resistance, and exhaustion. Thus, when the organism becomes deprived of resources, it is not necessarily that it 
becomes ill, but becomes more vulnerable to the disease and more permeable to various other factors that can lead to illness. There are three pathways in which stress exposure can affect health. The first pathway consists in physiological changes (endocrine and cardiovascular reactivity) as mediators between stress and illness. However, moderating factors such as personality, age or gender can also enter this equation (Weidner, 2001). Another mediator consists in health compromising behaviors (consuming more tobacco, alcohol, illicit drugs, unhealthy diet, lack of self-care) through which people try to relieve their tensions (Brannon \& Feist, 1997). The third mediator consists in negative affects (constant rumination, worrying, anger, pessimism, anxiety, depression) which most often accompany stressful events (Scheier \& Bridges, 1995).

Empirical research on adult samples shows that the accumulation of stressful life events heightens the risk of negative consequences, including mental health symptoms (Krause et al., 2004). These experiences can occur throughout life, from childhood, and their consequences can manifest in different ways and life contexts (Shmotkin \& Litwin, 2009).

It is unanimously accepted the idea that stress is detrimental to health, but not every individual develops health problems in the afterwards of stressful life events. Interpersonal differences play a special role in the nature and intensity of the consequences of aversive situations and on the individual responses to them. One of these personal factors is resilience.

\section{Resilience in adults}

Resilience is studied intensively and extensively, but without a unanimous opinion on its exact definition and its precise location in human psyche. There are currently three important approaches to resilience: i) personal trait - which helps the person to cope with adversity, successfully adapt to the changes produced by critical life events and to continue their development process; consists in personality traits that contribute to mitigating the impact of traumatic events (Connor \& Davidson, 2003; Ong, Bergman, Bisconti, \& Wallace, 2006); ii) outcome - behavioral outcome that challanges and helps individuals to recover from adversity (Harvey \& Delfabbro, 2004; Masten, 2001); process - a dynamic process by which individuals actively adapt and recover from critical life events (Fergus \& Zimmerman, 2005; Luthar, Cicchetti, \& Becker, 2000).

A large number of studies analyze resilience as an individual trait (Ong et al., 2006) or as an epiphenomenon of an adaptive temperament (Wachs, 2006). In other studies, coping from everyday life as a consistent personal resource is considered to be a facet of trait resilience, which functions as an enhancing factor for different types of adversity. There are studies that address resilience as a driving force for growth as a result of coping with adverse events (Richardson, 2002).

In this study we will address resilience as a trait and its relationships with stressful life events and general health status in adults. We consider such an approach necessary because resilience has been studied mainly in children and adolescents, starting from the idea that critical life events during childhood can lead to adverse consequences in the further development of children. The study of resilience has generally been aimed at mitigating the traumatic effects of adverse events suffered by children and implementing methods to improve resilience. In this case, we want to identify the factors that contribute to some extent to the development of resilience, as well as its role in the relationship between exposure to stressful life events and health in adults.

Bonanno (2004) defined adult resilience as the ability to maintain relatively stable levels of mental and physical functioning when faced with isolated adverse events or life-threatening situations, as well as the capacity for generative experiences and positive emotions. An interesting point in this view is that although resilient people experience certain short-term dysregulations and a relative decline in well-being, they do not impede the ability to function within acceptable parameters. Thus, resilient individuals, despite being exposed to critical events, maintain their ability to fulfill their personal and social responsibilities, as well as to be open to new experiences. These evidences have been supported by studies on bereavement (Bonanno, Moskowitz, Pope, \& Folkman, 2005) or on terrorist attacks (Bonanno, Rennicke, \& Dekel, 2005).

A higher level of resilience has been linked with both adaptive behaviors and a lower risk of deteriorating health. Thus, increasing resilience offers better opportunities for reintegration and maintaining homeostasis (Richardson, 2002). By understanding the factors that contribute to the development and strengthening of resilience, it is easier to understand the resilience construct itself, as well as to find ways to improve it (Muller, Ward, Winefield, Tsourtsos, \& Lawn, 2009).

At the same time, there are a multitude of factors that determine resilience, including genetic, biological, psychological, factors related to family, community or social context. They may interact with each other and may act differently depending on the nature of the adverse event (Cameron, Ungar, \& Liebenberg, 2007; Norris et al., 2008).

Psychological factors that have been linked to resilience include risk factors (depressive or anxious symptoms, high levels of stress) and protective factors (life satisfaction, optimism, self-efficacy, positive affect, social support). Regarding risk factors, cumulative exposure to stressful experiences causes a decrease in resilience. Although some experts believe that repeated exposure to stressful events leads to increased resilience (Seery et al., 2010; Seery, 2011), other researchers have shown that the large number of adverse events experienced causes emotional and behavioral problems (Herbes et al. , 2014).

\section{Resilience and mental health}

Relationships between resilience and health are a topic of interest for psychology research (Haskett et al., 2006; Windle, 2011). Mental resilience was defined as a quick recovery after stress (Tugade \& Fredrickson, 2004) and describes the individual's ability to return to the initial levels of mental, emotional, and cognitive activity after experiencing adverse events (functional limitations, marital separation, bereavement, poverty).

Numerous empirical studies have found that trait resilience was negatively linked with negative indicators of mental health (Burns \& Anstey, 2010; Abiola \& Udofia, 2011) and positively linked to positive indicators (Karaimak, 2010). At the same time, some indicators of mental health such as positive affect (Fredrickson et al., 2003; Xing \& Sun, 2013), depression (Hasui et al., 2009), anxiety (Beutel et al., 2010) were predicted by trait resilience.

A number of studies have shown that resilience contributes to diminishing depression and anxiety, 
providing protection when confronted with adverse events (Judd et al., 2003; Komiti et al., 2003). Logan-Greene, Green, Nurius, \& Longhi (2014), in a study involving 19,333 adults, found that resilience is a determinant factor of physical and mental health, along with other sociodemographic or individual factors.

\section{Present study}

The objective of the present study is to identify the relation pattern between exposure to stressful life events, resilience and mental health. In this sense, we formulate the hypothesis of the study: Resilience moderates the relationship between exposure to stressful life events and mental health.

\section{Method}

\section{Participants and procedure}

The research sample consists of 238 participants from the general Romanian population, aged between 23 and 68 years, $\mathrm{M}=44.16, \mathrm{SD}=11.03$. The participants are mostly women, $\mathrm{N}=188(79 \%)$ and for men $\mathrm{N}=50(21 \%)$. Of these, $127(53.4 \%)$ reported a level of education below 12 grades and $111(46.6 \%)$ a level of education of minimum 12 grades. Regarding marital status, $56(23.5 \%)$ are single and $188(76.5 \%)$ are married or in a relationship.

Participants completed the questionnaires online, being requested through social networks to participate in a study on resilience. The first section of the form included a brief description of the study and also the informed consent. The display of the items of the questionnaires was done only after the participants declared that they agreed to participate in the research. The online form distributed through Facebook has targeted (for a fee) a group of 3000 participants from different fields of activity, aged from 20 to 70 years, so the sample is a convenience one. The participants were not rewarded in any way. The study has a cross-sectional design

\section{Measures}

Stressful life events. To measure stressful life events we used Stressful Life Event Questionnaire (Roohafza et al., 2011). The instrument consists in a list of 46 stressful events inspired from The Holmes-Rahe Life Stress Inventory. The authors grouped the events in 11 categories such as home life, financial problems, social relations, personal conflicts, job conflicts, educational concerns, job security, loss and separation, sexual life, daily life, and health concerns. In our study, we used the items themselves and not the 11 subscales to calculate the number of stressful events experimented by participants.
The responses were dichotomous, where 0 - never happened to me, and 1 - happened to me. Examples of items: "Divorce or separation", "Death of a close family member", "Not having an intimate friend". Scores ranged between 0 and 46 . The Cronbach index of internal consistency was $\alpha=.87$.

Resilience was measured with Resilience Scale, RS-14 (Wagnild \& Young, 2009). Initially, the instrument comprised 25 items, later it was reduced to 14 items to reduce the time required for completion. When reducing the number of items, those with high inter-item correlations were maintained. Example of an item: "I find things to cheer me on". The answers are given on a 7-step Likert scale where 0 - never and 6 - always. The Cronbach index of internal consistency was $\alpha=.95$.

Mental health was measured with General Health Questionnaire, GHQ-12. This is the most extensively used screening instrument for common mental disorders and a general measure of psychiatric well-being. GHQ-12 is a 12 items screening instrument scored on a 4-step Likert scale, where 0 - never and 3 - always. Example of item: "Been able to concentrate on whatever you are doing". The Cronbach index of internal consistency was $\alpha=.81$.

The instruments were translated and back-translated together with two experts.

\section{Results}

In order to organize the data and test the hypothesis, we used IBM.SPSS.24 (IBM Corp, 2016) and the medmod module of JAMOVI (The jamovi project, 2019). Means, standard deviations, and correlations among investigated variables in this study are presented in Table 1.

$\mathrm{H} 1$. Resilience moderates the relationship between exposure to stressful events and mental health.

To test this hypothesis we ran a moderation analysis. Firstly, a hierarchical regression analysis was conducted to verify if there is a potential moderation of resilience in the relationship between exposure to stressful life events and health. The two models were statistically significant, model 1 - exposure to stressful life events and resilience predict mental health, $\mathrm{F}(2,235)=105.97, \mathrm{p}<.01$ and model 2 interaction between exposure to stressful life events and resilience predict mental health, $\mathrm{F}(3,234)=75.01, \mathrm{p}<.01$. Model 2 accounted for more variance than model $1, \mathrm{R}^{2}$ change $=.02, \mathrm{p}=.007$, indicating that there is potentially significant moderation between exposure to stressful life events and resilience on mental health. The moderation results appear in Table 2, while the effects of exposure to stressful life events on general health at different levels of resilience are presented in Table 3.

Table 1. Means, standard deviations, and correlations among study variables

\begin{tabular}{lllllllll} 
& $\mathrm{M}$ & $\mathrm{SD}$ & 1 & 2 & 3 & 4 & 5 & 6 \\
\hline 1. Gender & - & - & 1 & & & & \\
2. Age & 44.16 & 11.03 & $.15^{*}$ & 1 & & & \\
3. Educational level & - & - & .03 & -.09 & 1 & & \\
4. Marital status & - & - & .10 & .11 & -.12 & 1 & \\
5. Exp. to life stress & 14.61 & 7.79 & .02 & -.12 & -.01 & $-.18^{* *}$ & 1 \\
6. Resilience & 59.44 & 17.88 & -.03 & $.25^{* *}$ & $.24^{* *}$ & .11 & $-.16^{*}$ & 1 \\
7. General health & 20.36 & 6.68 & -.02 & $.14^{*}$ & $.29^{* *}$ & $.15^{*}$ & $-.28^{* *}$ & $.67^{* *}$ \\
\hline
\end{tabular}


Table 2. Moderation results

\begin{tabular}{|c|c|c|c|}
\hline Variables & $R^{2}$ & $\Delta R^{2}$ & $\beta$ \\
\hline Model 1 & $.47 * *$ & & \\
\hline Exposure to stressful events & & & $-.14 * *$ \\
\hline Resilience & & & $.26^{* *}$ \\
\hline Model 2 & .49 & $.02 * *$ & \\
\hline Exposure to stressful events & & & $-.14 * *$ \\
\hline Resilience & & & $.25 * *$ \\
\hline Exposure*Resilience & & & $-.01 * *$ \\
\hline
\end{tabular}

Notes: $* * . p<.01$.

Table 3. Effect of exposure to stressful life events on general health at different levels of resilience

\begin{tabular}{|c|c|c|c|c|c|c|}
\hline & \multicolumn{6}{|c|}{ 95\% Confidence Interval } \\
\hline & Estimate & SE & Lower & Upper & $\mathrm{Z}$ & $\mathrm{p}$ \\
\hline Average & -.14 & .04 & -.22 & -.06 & -3.54 & $<.001$ \\
\hline Low (-1SD) & -.04 & .06 & -.15 & .07 & -.69 & .492 \\
\hline High $(+1 \mathrm{SD})$ & -.25 & .05 & -.35 & -.14 & -4.52 & $<.001$ \\
\hline
\end{tabular}

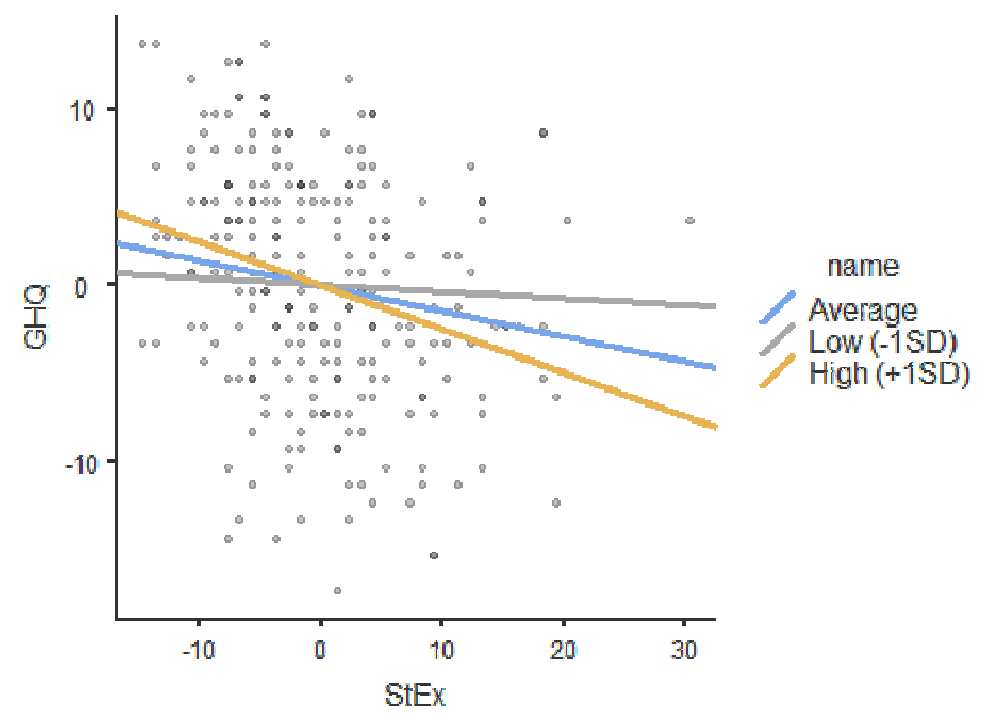

Figure 1. Graphic representation of moderation analysis

Results showed that resilience moderates the relationship between exposure to stressful events and health. Exposure to stressful life events decreases health state, $\beta=-.14, p<.01$, resilience increases health state, $\beta=$ $.25, \mathrm{p}<.01$, and interaction between exposure to stressful life events and resilience is statistically significant. At lower levels of resilience (scores lower than 41), exposure to stressful life events does not significantly influence health, at average levels of resilience (scores between 42 and 69) exposure to stressful life events decreases health state $(-.14, \mathrm{p}<.01)$, and at the same time, at higher levels of resilience (scores higher than 70) exposure to stressful life events also decreases health state $(-.25, \mathrm{p}<.01)$.

\section{Discussion}

The results of the present study showed that resilience moderates the relationship between exposure to stressful situations and health. The negative relationship between exposure to stressful life events and mental health becomes non-significant at lower levels of resilience. However, high levels of resilience, contrary to our expectations, fail to combat the effects of critical life events, which in turn have a negative influence on the health of the individual. These results can be caused by the exhaustion of resources that the individuals use when they have to deal with adverse events, which can lead to deterioration of health state in order to protect personal safety and integrity. 
It is interesting that a higher level of resilience leads to stronger negative effects of stressful life events on health. Trait resilience has two component elements, respectively personal competence and acceptance of self and life. The more the individuals feel competent to solve their personal problems and the more easily they accept the adverse situations of life, the higher the price they pay. In order to maintain their homeostasis when faced with stressful events, they consume important resources, and this consumption leads to the deterioration of the health state.

The adverse effects of stressful events on health state have been documented in numerous studies. Thus, LoganGreene et al. (2014) showed that adverse childhood events are associated with poor health even when other variables have been controlled (age).

The results obtained by us are contrary to those obtained in other studies. For example, Roy et al. (2011) suggested that resilience may play a protective role against suicide risk in people who have suffered childhood trauma. Also, Nrugham et al. (2010), in a longitudinal study involving 2.464 students, showed that resilience moderates the relationship between life violent events and suicide attempts. Campbell-Sills et al. (2006) found that resilience can moderate the relationship between early trauma and present symptoms.

Although resilience has been shown to prevent health problems in a very high percentage, this is not the only determinant of health. As long as the risk factors have a greater share in the lives of individuals, resilience may not be sufficient to maintain their health as a result of experiencing traumatic situations.

\section{Practical implications}

In this study, trait resilience has failed to improve the effects of critical life events on health status, which causes us to consider other aspects of human psyche when it comes to reducing the impact of adverse life events. Thus, in the psychotherapeutic practice or in the programs of personal development, elements related to other aspects can be introduced that can contribute to the improvement of the well-being and to the post-traumatic growth of the person. These may include: developing supportive interpersonal relationships, self-care good practices and health oriented behaviors, proactive attitudes toward adversities, learning strategies that have worked in other life contexts, view adversity as normal.

\section{Limitations and future research directions}

One of the limitations of the present study is the imbalance between the number of male and female participants, which prevented us from performing differential analyzes. It should be mentioned that this approach is the preamble to a larger study in which more people will participate.

Another limitation of the study is the interpretation of exposure to stressful life events, in terms of number of events and not in terms of magnitude of impact. Also, the timing of the events was not highlighted, which could have contaminated the results because some of the events may have occurred long time ago and their effects may have been blurred, while others may have been recent and their effects may have been acute. Our intention is to control these shortcomings by applying instruments that more accurately capture the dimensions of stressful events, as well as other protective and vulnerability factors that influence resilience. Moreover, resilience should be analyzed also as a process or as a result, not just as a personality trait.

\section{References}

Abiola, T., \& Udofia, O. (2011). Psychometric assessment of the Wagnild and Young's resilience scale in Kano, Nigeria. BMC Research Notes, 4, 509.

Baltes, P. B., Baltes, M. M. (editors). (1990). Successful aging: Perspectives from the behavioral sciences. New York: Cambridge University Press.

Beutel, M. E., Glaesmer, H., Decker, O., Fischbeck, S., \& Brahler, E. (2009). Life satisfaction, distress, and resiliency across the life span of women. The Journal of North American Menopause Society, 16, 1132-1138.

Beutel, M. E., Glaesmer, H., Wiltink, J., Marian, H., \& Brahler, E. (2010). Life satisfaction, anxiety, depression and resilience across the life span of men. Aging Male, 13, $32-39$.

Bonanno, G. A. (2004). Loss, trauma, and human resilience: Have we underestimated the human capacity to thrive after extremely aversive events? American Psychologist, $59,20-28$.

Bonanno, G. A., Moskowitz, J. T., Papa, A., \& Folkman, S. (2005). Resilience to loss in bereaved spouses, bereaved parents, and bereaved gay men. Journal of Personality and Social Psychology, 88, 827-843.

Bonanno, G. A., Rennicke, C., \& Dekel, S. (2005). Selfenhancement among high-exposure survivors of the September 11th terrorist attack: Resilience or social maladjustment? Journal of Personality and Social Psychology, 88, 984-998.

Brannon, L., \& Feist, J. (1997). Health psychology. An introduction to behavior and health. Pacific Grove, CA: Brooks/Cole.

Brewin, C. R., Andrews, B., Valentine, J. D. (2000). MetaAnalysis of Risk Factors for Posttraumatic Stress Disorder in Trauma-Exposed Adults. Journal of Consulting and Clinical Psychology, 68(5), 748-766.

Burns, R. A., \& Anstey, K. J. (2010). The Connor-Davidson resilience scale (CD-RISC): Testing the invariance of a uni-dimensional resilience measure that is independent of positive and negative affect. Personality and Individual Differences, 48, 527-531.

Cameron, C. A., Ungar, M., \& Liebenberg, L. (2007). Cultural understandings of resilience: Roots for wings in the development of affective resources for resilience. Child and Adolescent Psychiatric Clinics of North America, 16, 285-301.

Campbell-Sills, L., Forde, D. R., \& Stein, M. B. (2009). Demographic and childhood environmental predictors of resilience in a community sample. Journal of Psychiatric Research, 43, 1007-1012.

Campbell-Sills, L., Cohan, S.L., Stein, M.B. (2006). Relationship of resilience to personality, coping, and psychiatric symptoms in young adults. Behaviour Research and Therapy, 44(4), 585-599.

Connor, K. M., \& Davidson, J. R. T. (2003). Development of a new resilience scale: The Connor-Davidson resilience scale (CD-RISC). Depression and Anxiety, 18, 76-82.

Fergus, S., \& Zimmerman, M. A. (2005). Adolescent resilience: A framework for understanding healthy development in the face of risk. Annual Review of Public Health, 6, 399-419.

Fredrickson, B. L., Tugade, M. M., Waugh, C. E., \& Larkin, G. R. (2003). What good are positive emotions in crises: A prospective study of resilience and emotions following the terrorist attacks. Journal of Personality and Social Psychology, 84, 365-376.

Gillespie, B. M, Chaboyer, W., \& Wallis, M. (2009). The influence of personal characteristics on the resilience of 
operating room nurses: A predictor study. International Journal of Nursing Studies, 46, 968-976.

Harvey, J., \& Delfabbro, P. H. (2004). Psychological resilience in disadvantaged youth: A critical overview. Australian Psychologist, 39, 3-13.

Haskett, M. E., Nears, K., Sabourin Ward, C., \& McPherson, A. V. (2006). Diversity in adjustment of maltreated children: Factors associated with resilient functioning. Clinical Psychology Review, 26, 796-812.

Hasui, C., Igarashi, H., Shikai, N., Shono, M., Nagata, T., \& Kitamura, T. (2009). The resilience scale: A duplication study in Japan. The Open Family Studies Journal, 2, 1522.

Herbes, J. E., Cutuli, J. J., Monn, A. R., Narayan, A. J., \& Masten, A. S. (2014). Trauma, adversity, and parent-child relationships among young children experiencing homelessness. Journal of Abnormal Child Psychology, 42(7), 1167-1174.

Horowitz, M. J. (1976). Stress response syndromes. New York: Jason Aronson. Janoff-Bulman, R. (1992). Shattered assumptions: Towards a new psychology of trauma. New York: Free Press.

IBM Corp. Released 2016. IBM SPSS Statistics for Windows, Version 24.0. Armonk, NY: IBM Corp.

Judd, F., Cockram, A., Davis, J., Fahey, A., Hodgins, G., Jackson, H., et al. (2003).First year of practice visits for the rural depression anxiety research and treatment general practice program. Australian Journal of Rural Health, $11(4), 175-180$.

Karairmak, O. (2010). Establishing the psychometric qualities of the Connor-Davidson resilience scale (CD-RISC) using exploratory and confirmatory factor analysis in a trauma survivor sample. Psychiatry Research, 179, 350356.

Komiti, A., Judd, F., Grech, P., Mijch, A., Hoy, J., Williams, B., et al. (2003). Depression in people living with HIV/AIDS attending primary care and outpatient clinics. Australian and New Zealand Journal of Psychiatry, 37(1), 70-77.

Krause, N., Shaw, B. A., Cairney, J. A. (2004). Descriptive epidemiology of lifetime trauma and the physical health status of older adults. Psychology and Aging, 19, 637-648.

Lamond, A. J., Depp, C. A., Allison, M., Langer, R., Reichstadt, J., Moore, D. J.,... Jeste, D. V. (2008). Measurement and predictors of resilience among community-dwelling older women. Journal of Psychiatric Research, 43, 148-154.

Logan-Greene, P., Green, S., Nurius, P. S., Longhi, D. (2014). Distinct Contributions of Adverse Childhood Experiences and Resilience Resources: A Cohort Analysis of Adult Physical and Mental Health. Social Work Health Care, 53(8), 776-797.

Luthar, S. S., Cicchetti, D., \& Becker, B. (2000). The construct of resilience: A critical evaluation and guidelines for future work. Child Development, 71, 543-562.

Lutz, W., Samir, K. C. (2011). Global human capital: integrating education and population. Science, 333, 587592.

Muller, R., Ward, P. R., Winefield, T., Tsourtos, G., \& Lawn, S. (2009). The importance of resilience of primary care practitioners: An interactive psycho-social model. Australasian Medical Journal, 1, 1-15.

Nrugham, L., Holen, A., Sund, A.M. (2010). Associations between attempted suicide, violent life events, depressive symptoms, and resilience in adolescents and young adults. The Journal of Nervous and Mental Disease, 198(2), 131136.

Nolen-Hoeksema, S., \& Morrow, J. (1991). A prospective study of depression and posttraumatic stress symptoms after a natural disaster: The 1989 Loma Prieta earthquake. Journal of Personality and Social Psychology, 61, 115121.

Norris, F. H., Stevens, S. P., Pfefferbaum, B., Wyche, K. F., \& Pfefferbaum, R. L. (2008). Community resilience as a metaphor, theory, set of capacities, and strategy for disaster readiness. American Journal of Community Psychology, 41, 127-150.

Ong, A. D., Bergeman, C. S., Bisconti, T. L., \& Wallace, K. A. (2006). Psychological resilience, positive emotions, and successful adaptation to stress in later life. Journal of Personality and Social Psychology, 91, 730-749.

Richardson, G. E. (2002). The metatheory of resilience and resiliency. Journal of Clinical Psychiatry, 58, 307-321.

Roohafza, H., Ramezani, M., Sadeghi, M., Shahnam, M., Zolfagari, B., Sarafzadegan, N. (2011). Development and validation of the stressful life event questionnaire. International Journal of Public Health, 56, 441-448.

Roy, A., Carli, V., Sarchiapone, M. (2011). Resilience mitigates the suicide risk associated with childhood trauma. Journal of Affective Disorders, 133(3), 591-594.

Scheier, M. F., \& Bridges, M. W. (1995). Person variables and health: Personality predispositions and acute psychological states as shared determinants for disease. Psychosomatic Medicine, 57, 255-268.

Schulz, R., Heckhausen, J. (1996). A life span model of successful aging. American Psychologist, 51, 702-714.

Seery, M. D. (2011). Resilience A silver lining to experiencing adverse life events? Current Directions in Psychological Science, 20(6), 390-394.

Seery, M. D., Holman, E. A., \& Silver, R. C. (2010). Whatever does not kill us: cumulative lifetime adversity, vulnerability, and resilience. Journal of Personality and Social Psychology, 99(6), 1025-1041.

Selye, H. (1956). The stress of life. New York: McGraw-Hill.

Shaham, Y., Singer, J. E., \& Schaeffer, M. H. (1992). Stability/instability of cognitive strategies across tasks determine whether stress will affect judgmental processes. Journal of Applied Social Psychology, 22, 691-713.

Shmotkin, D., Litwin, H. (2009). Cumulative adversity and depressive symptoms among older adults in Israel: the differential roles of self-oriented versus other-oriented events of potential trauma. Social Psychiatry \& Psychiatric Epidemiology, 44, 989-997.

Strauss, J., Thomas, D. (2008). Health over the life course. In: T. P. Schultz \& J. Strauss (eds), Handbook of development economics, vol. 4. (pp. 3375-3474). Amsterdam, Nederlands: North-Holland Biomedical Press.

The jamovi project (2019). jamovi. (Version 0.9) [Computer Software]. Retrieved from https://www.jamovi.org.

Tugade, M.M., \& Fredrickson, B.L. (2004). Resilient individuals use positive emotions to bounce back from negative emotional experiences. Journal of Personality and Social Psychology, 86, 320-333.

Wachs, T. D. (2006). Contributions of temperament to buffering and sensitization processes in children's development. Annals of the New York Academy of Sciences, 1094, 28-39.

Wagnild, G. M., \& Young, H. M. (1993). Development and psychometric validation of the Resilience Scale. Journal of Nursing Measurement, 1, 165-178.

Weidner, G. (2001). Why do men get more heart disease than women? An international perspective. Journal of American College Health, 48, 291-294.

Windle, G. (2011). Psychological resilience as a resource for later life. Gerontologist, 51, 331 .

Xing, C., \& Sun, J. M. (2013). The role of psychological resilience and positive affect in risky decision-making. International Journal of Psychology, 48, 935-943. 